\title{
Comparison of three solar water heaters technologies through a full-scale experimental station
}

\author{
Youssef Boukdir ${ }^{1 *}$, and Hamid El Omari ${ }^{1}$ \\ ${ }^{1}$ Laboratory of Renewable Energies Environment and Development, Hassan $1^{\text {st }}$ University, Faculty of Science and Technology Settat \\ City, Morocco
}

\begin{abstract}
The aim of the solar water heater designed for Tahala grid project, is to provide renewable energy to the residents of Tahala village in southern of Morocco, our contribution as LERED* laboratory to this project consists of the creation of a novel solar water heater, with a long lifetime, high efficiency, reliability and quality, that uses solar concentration instead of direct exposition in the hope of reaching high temperatures even during cold weather and the winter season. In order to evaluate the performances of this new solar water heater, it was necessary to build a full-scale solar water heater test bench station, which allows to monitor the thermal station remotely, in order to start new experiments, measure various parameters such as cumulated thermal energy, the maximum reached temperature, efficiency, and so on, in order to compare the performances of each solar water heating technology in various weather conditions. In this study, we choose to test and compare three solar water heater technologies: water-in-glass evacuated tube collectors, selective surface flat-plate collectors, and the novel design that consists of a Fresnel mirrors concentrator with a water-in-glass evacuated tube collector with a dual sun tracking system. The result of experiments shows that under normal weather conditions, the Fresnel mirrors concentrator efficiency reached $48 \%$, followed by the evacuated tube collector that have an efficiency of $42.3 \%$, and then come at the last position the flat-plate collector with an efficiency $36.3 \%$.
\end{abstract}

** Laboratoire des Energies Renouvelables Environnement et Développement (Renewable Energies Environment and Development Laboratory)

*Corresponding author:y.boukdir@uhp.ac.ma 


\section{Introduction}

Nowadays all climate scientists have concluded that our planet is facing colossal environmental disasters, such as melting glaciers, rising sea levels, and desertification, all these phenomena are mainly linked to global warming that is caused by the increase in greenhouse gas emissions due to the increase in polluting industrial activities since the industrial revolution [1].

Depending on climate specifications of each geographic area, many renewable sources of energy solutions can be suggested [2,3], in order to solve the energy crisis, global warming, and climate change, one of the most abundant renewable sources of energy is solar energy [4], it can be exploited to produce thermal energy by using solar concentrators such as Fresnel mirrors concentrators [5] and parabolic trough collectors [6].

In this study, we chose solar water heaters as an application, to exploit solar thermal energy, and further on, we built a full-scale experimental station, to test three solar water heaters technologies: water-in-glass evacuated tube collectors $[7,8]$, selective surface flatplate collectors $[9,10]$ and Fresnel mirrors concentrator with a water-in-glass vacuum tube collector with a dual sun tracking system, to be able to compare and evaluate the performance of each one of them in various weather conditions, all over the year $[11,12]$.

\section{Tools and method}

To compare and evaluate each solar water heater technology, it has been necessary to build a full-scale experimental station containing all these technologies, this thermal station is located on the roof of faculty of science and technology of Settat city in Morocco, and it supplies hot water to students and administrative staff.

The thermal station is divided into two floors, the top floor (the roof) contains the three solar water heaters, while the bottom floor (control room) contains the majority of electric components, isolated hot water storage tanks, hot water pumps, valves, solenoid valves, and so on, the two floors are connected to each other by electric cables, network cables, in addition to hot and cold water pipes.

The station is equipped with many sensors; all connected to a computer (raspberry pi 3 ) in order to record the measurements and be able to remotely monitor the station, run new experiments and get their final results.

\subsection{Hydraulic circuit}

The hydraulic circuit starts with the general water supply valve that isolates the whole station from the rest of the building circuit, a pressure regulator and a manometer has been installed in order to reduced and keep water pressure at the desired value to protect the hydraulic installation from any overpressure, comes next a $5 \mu \mathrm{m}$ fine filter to remove harmful particles present in the water and which can prematurely reduce the life of the components of the hydraulic system, then the water passes through a water flow sensor, which indicates the water quantity passed through the whole thermal station, after that, the cold water is distributed to each solar water heater circuit.

In order to simplify the management of water flows inside the thermal station, as well as its maintenance, each segment of the hydraulic circuit, has a valve or a solenoid valve, this arrangement makes it possible to isolate a segment, a group of segments, or even to

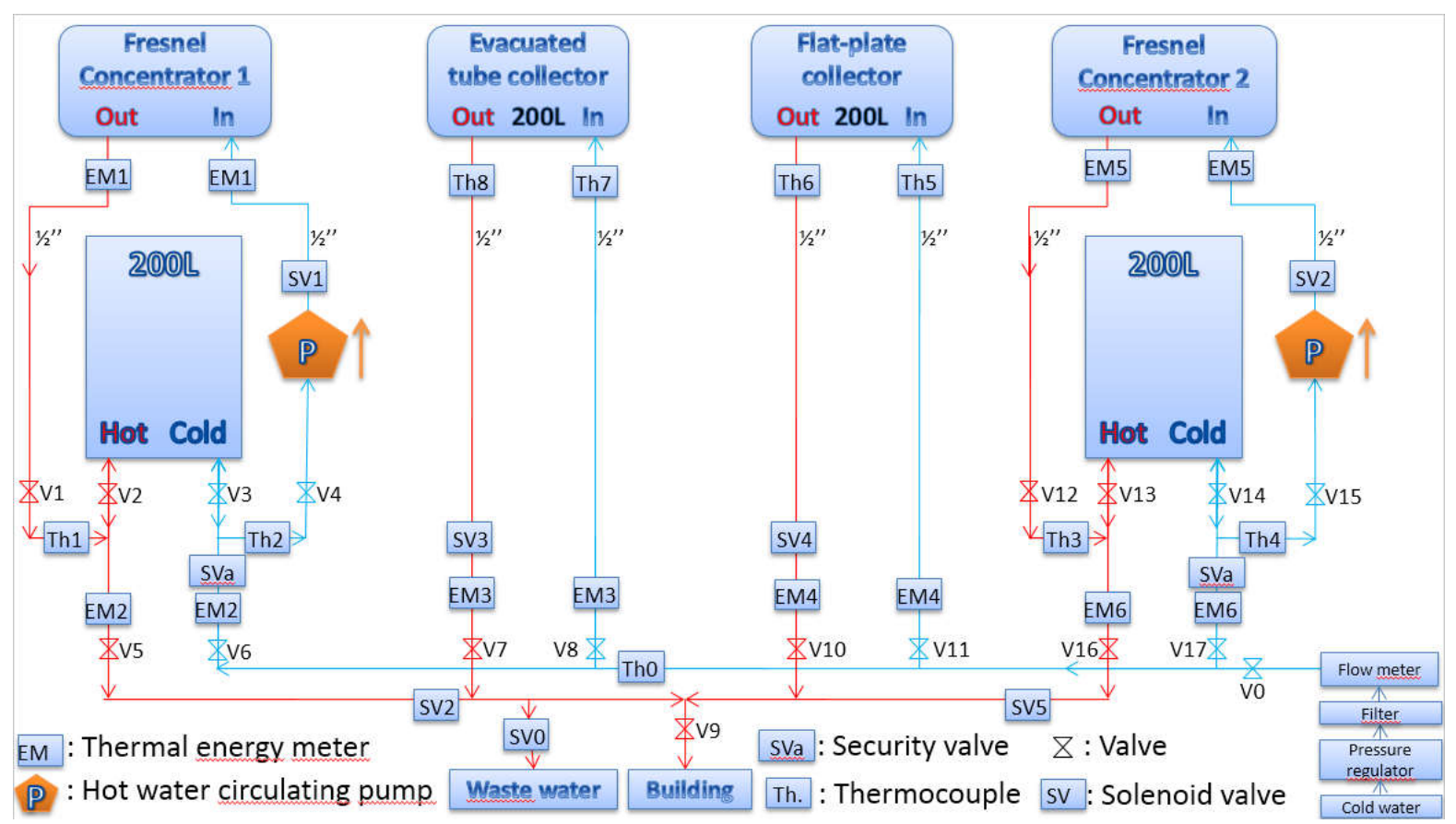

Fig. 1. Hydraulic circuit of the thermal station. 
isolate a whole water heater circuit from the rest of the thermal station circuit without disturbing the operation of the rest of the hydraulic circuit.

In every specific point of interest of the hydraulic circuit, many sensors were used to collect data such as temperature sensors, water flow sensors and thermal energy meters.

The temperature sensors used are ungrounded K-type thermocouples $[13,14]$, that have been immersed into the water pipes to be in direct contact with circulating water, in order to measure precisely and continuously the water temperature in each segment of the hydraulic circuit and for each solar water heater, all thermocouples are connected to a data logger electronic card that records these data for analysis.

The water flow sensors allow to measure the water quantity consumed by users or traveled through a pipe segment or a pipe loop.

Thermal energy meters allows to measure the quantity of thermal energy produced by each solar water heater, they are composed of a high precision geared water flow sensor [15] and two ungrounded K-type thermocouples, the thermocouples measures respectively the inlet et outlet temperature of a pipe segment or loop, and the water flow sensor count the number of litters that passes through it and at which temperature, after processing the collected data using thermodynamic equation, the thermal energy produced is calculated and stored for analyze.

Safety valves have been installed at each critical point of the hydraulic circuit in order to avoid any incident following the confinement of the vapors and the overpressures inside the hydraulic circuit.

Both evacuated tube collector and flat-plate collector use thermosiphon effect to create cold and hot water circulation inside their hydraulic circuitry, while Fresnel mirrors concentrator uses forced water circulation $[16,17]$ because of the absolute necessity of tracking the sun movements during the day on its two axes, which implies that it is difficult to exploit the thermosiphon effect, which impose to install the water storage tank as close as possible from the concentrator to avoid heat losses during water transition in pipes, in this case, the hot water storage tanks are installed on the floor below, just under the location of the concentrator.

A hot water circulating pump is used in order to bring up cold water from water storage tank located in the technical room to Fresnel mirrors concentrator on the roof, the cold water passes through the evacuated tube collector, then returns back to the storage tank.

The hot water circulating pump starts and stops accordingly to algorithmic rules, which are based on thermocouples data, and managed automatically by the use of an electronic control card integrated into the Fresnel mirrors concentrator.

The advantage of using forced circulation compared to the thermosiphon effect is that forced circulation allows better control of hot water flow [16-18], and therefore imposes water circulation according to a strategy that allows to minimize the losses due to water transition in pipes.

A solenoid valve is installed after each hot water circulating pump and activated only when the pump is energized, in order to avoid the unwanted circulation of hot water during the night or cold weather, caused by the thermosiphon effect due to the fact that the water temperature inside the storage tank is higher than the water temperature inside pipes and the evacuated tube collector on the roof, which can cause a lot of thermal energy losses.

\subsection{Electronic and electric circuit}

In addition to the previous sensors, electrical energy meters has been installed for each storage tank and hot water pump, this makes it possible to measure the amount of electrical energy consumed by the tank's

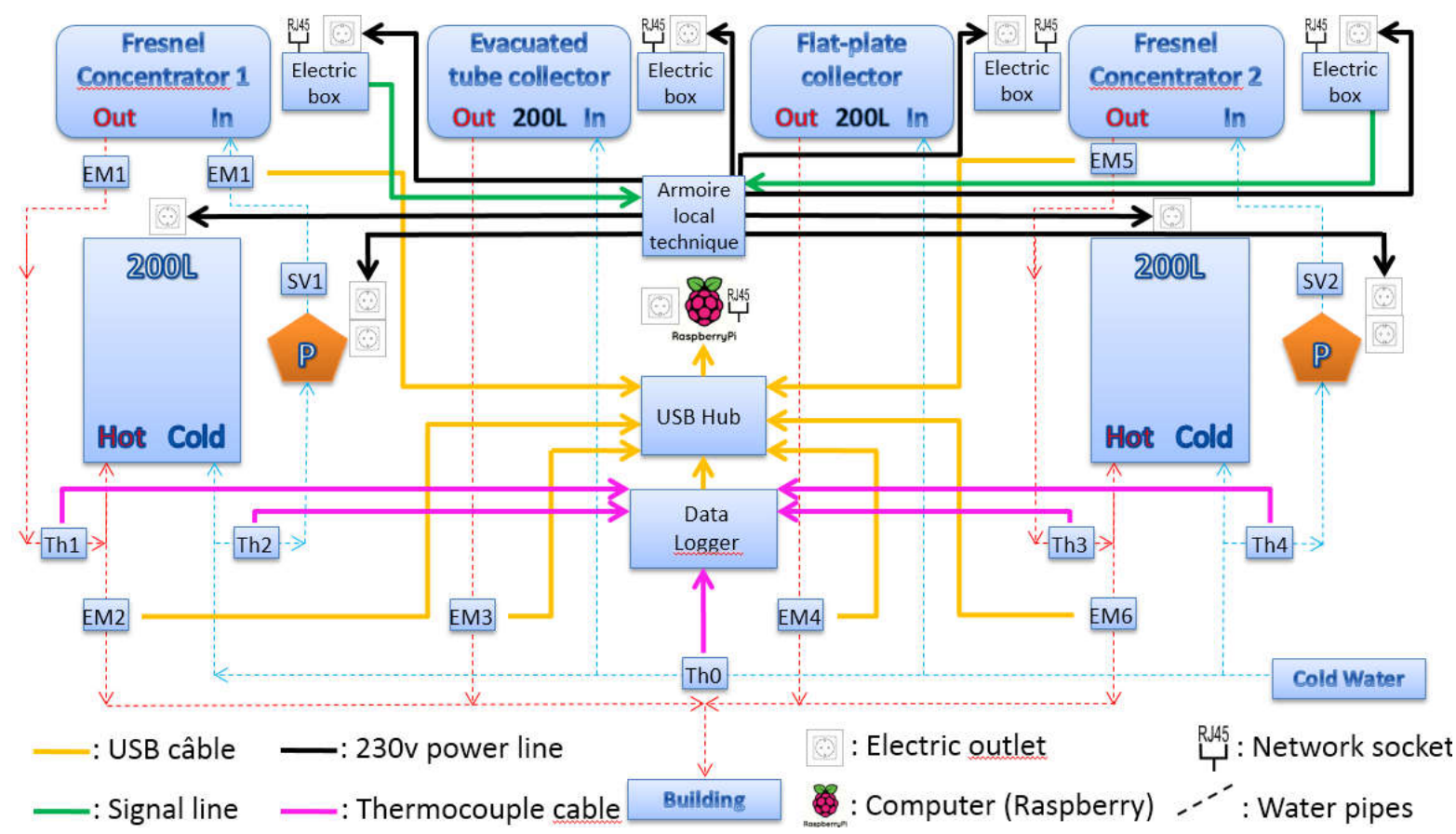

Fig. 2. Simplified electric circuit of the thermal station 
electrical backup system in case of cloudy and rainy days, as well as the electrical energy consumed by the hot water circulating pumps.

The electrical box in the control room contains a threephase general circuit breaker which protects the entire station, while each solar water heater has its own circuit breaker, which allows each solar water heater to be electrically isolated in order to be able to work on its circuitry and maintain it safely, while leaving the rest of the station operational; in addition to that and in case of an electric problem, only the circuit breaker of the concerned solar water heater is triggered, while the rest of the station is not affected.

Each solar water heater have a waterproof electrical box near to it, in order to protect its electronic devices; it contains also a $230 \mathrm{~V}$ (AC) electric outlet and a RJ45 network socket connected to the local area network.

The control room is equipped with a computer (Raspberry) which centralize all the data measured on the thermal station.

An USB hub is used upstream of the computer to remedy the limited number of USB ports present on computer, in order to be able to record all thermal energy meters, data loggers, pyranometer, and also update sun tracking systems' firmware if needed.

The computer is equipped with a backup battery in case of a power cut, which keeps the computer, as well as the whole electronic devices connected to it, running for 6 hours.

\section{Comparative study}

The comparative study is made between these three technologies shown in table 1 .

Table 1. Dimensional characteristics of the compared solar water heaters

\begin{tabular}{|c|c|c|c|}
\hline Technology & $\begin{array}{c}\text { Fresnel } \\
\text { Concentrator }\end{array}$ & $\begin{array}{c}\text { Evacuated } \\
\text { tube collector }\end{array}$ & $\begin{array}{c}\text { Flat-plate } \\
\text { collector }\end{array}$ \\
\hline Length $(\mathrm{m})$ & 1.22 & 1.90 & 1.09 \\
\hline Width $(\mathrm{m})$ & 1.9 & 1.66 & 1.81 \\
\hline Area $\left(\mathrm{m}^{2}\right)$ & 2.30 & 3.15 & 1.97 \\
\hline Capacity $(\mathrm{L})$ & 200 & 200 & 200 \\
\hline
\end{tabular}

The comparative study was done on 29 July 2021 on a sunny day with some passing clouds (cumulus clouds), the initial water temperature was $27^{\circ} \mathrm{C}$ and the ambient temperature was between $21^{\circ} \mathrm{C}$ and $31^{\circ} \mathrm{C}$, the sunrise at 05:42 GMT and the sunset at 20:32 GMT.

In order to have a coherent data collection, the experiment starts by cleaning all active surfaces from dust and dirt, then draining all hot water contained inside storage tanks, in order to have the same initial water temperature everywhere, this operation is done remotely by opening all draining solenoid valves (SV0, SV2, SV3, and SV4) one night before the start of the experiment, after finishing hot water draining, the 4 draining solenoid valves are closed to avoid any hot water consumption during the day period, otherwise, there would be an alteration of the data collection.

Then the pyranometer software and data logger software are started to record sensors returned values, in addition to that, the Fresnel mirrors concentrator's thermal energy meters (EM1 and EM2) also start record energy production, because of the fact that the water storage tank is far from the concentrator, so during the day period, there is a water circulation approximately every 15 minutes to store the hot water produced, while the evacuated tube collector and flatplate collector don't need any water circulation knowing that the storage tanks are integrated to the solar water heater structures.

Once the sun rises, the 3 solar water heaters start to collect and store solar energy received all day long, the Fresnel mirrors concentrator tracks the sun from sunrise to sunset, and each time the water temperature inside the evacuated tube collector reaches a preset threshold, the hot water circulating pump starts to drain hot water from it to store it into the storage tank, at the same time, a new volume of water (3.225 liters) is put it inside the evacuated tube for another heating cycle, and so on, while the evacuated tube collector and flat-plate collector don't need any automation to heat water.

At the end of the day and just after the sunset, the Fresnel mirrors concentrator, evacuated tube collector and flat-plate collector thermal energy meters start recording data (EM2, EM3, EM4), then the draining solenoid valves are opened again simultaneously (SV0, SV2, SV3, and SV4), then hot water starts to flow from the 3 storage tanks, and passes through the three thermal energy meters, by using thermodynamic equations, all collected data is then processed, in order to calculate how many Watt-Hour (Wh) of solar energy was collected by each technology, under the same weather conditions.

\section{Results and discussions}

As shown in figure 3 , the pyranometer registered a peak power of $1026 \mathrm{Watt} / \mathrm{m}^{2}$ at 13:31:00, and total radiation energy receive during the day period of 7470 Watt-hour $/ \mathrm{m}^{2}$, the spikes on the sun power radiation curve indicate the cross of the clouds over the thermal station, which cause an instantaneous drop in solar power.

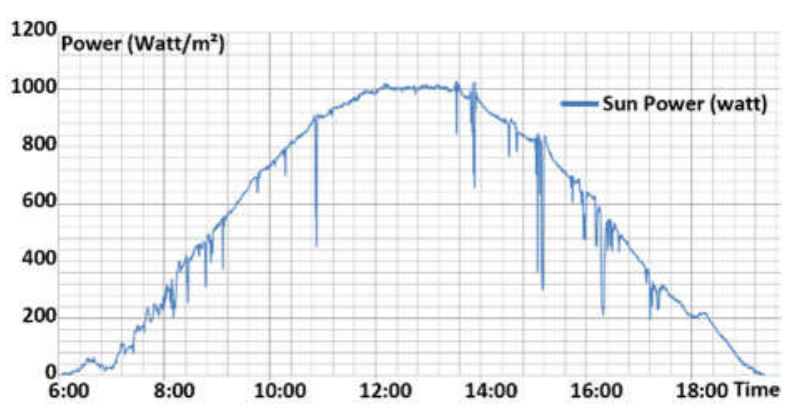

Fig. 3. Sun power radiation measured by the pyranometer.

After draining the evacuated tube collector, the obtained curve figure 4 shows that the maximum reached water temperature is $68.50^{\circ} \mathrm{C}$ while the extracted thermal energy is $9956 \mathrm{Wh}$. 


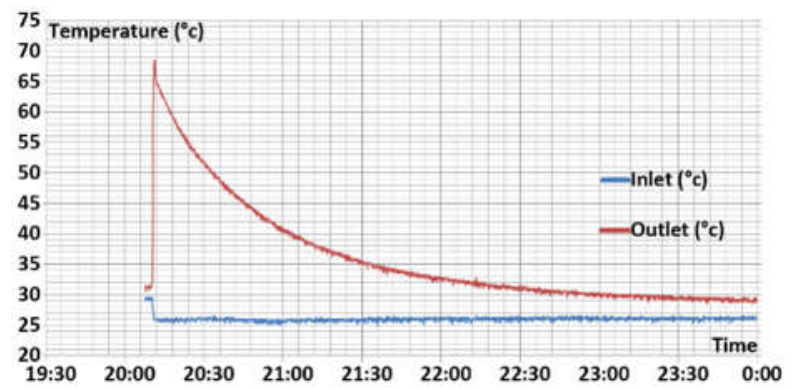

Fig. 4. EM3 - draining evacuated tube collector's storage tank at the end of the day.

Figure 5 shows that after draining the flat-plate collector, the maximum reached water temperature is $54.25^{\circ} \mathrm{C}$, while the extracted thermal energy is 5357 Wh.

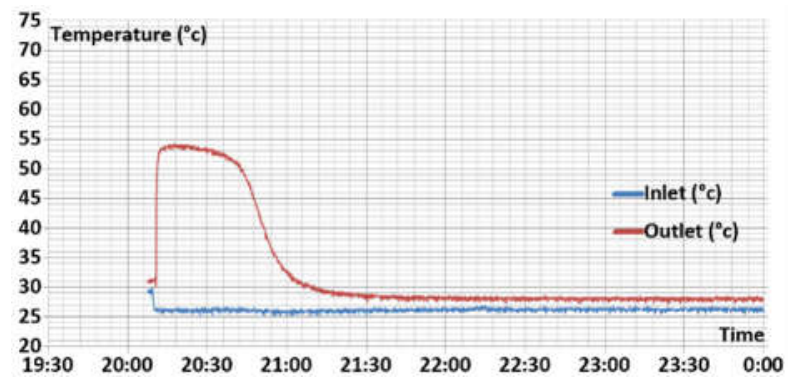

Fig. 5. EM4 - draining flat-plate collector's storage tank at the end of the day.

Figures $6 \& 7$ shows the operating behavior of the Fresnel mirrors concentrator during the day period, each peak of the red curve correspond to a water heating cycle inside the evacuated tube collector, that correspond to $3.225 \mathrm{~L}$ heated to $90^{\circ} \mathrm{C}$, the time interval between each cycle depends on the solar power, at the morning the interval is 23 minutes while at midday the period cycle can reach 12 minutes, and at the end of the day, it can be up to 30 minutes. The total hot water produced during this day is $112.87 \mathrm{~L}$ at $90^{\circ} \mathrm{C}$, which represents a thermal energy of $8256 \mathrm{Wh}$.

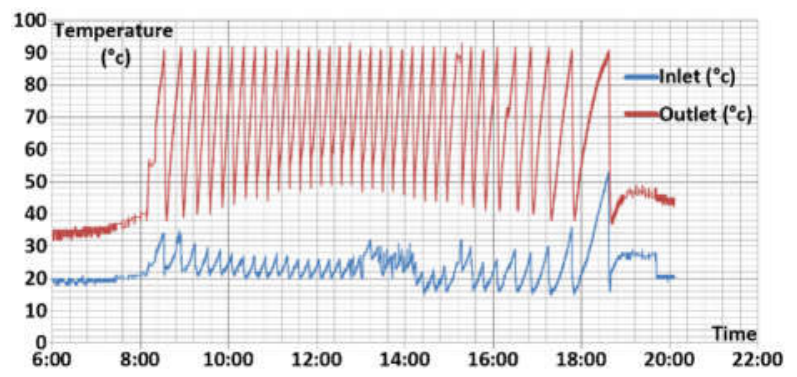

Fig. 6. EM1 - Monitoring evacuated tube collector's inlet and outlet temperatures during day period.

Figure 7 shows the temperature at the inlet and the outlet of the storage tank, the hot water coming from the evacuated tube collector loses a part of its thermal energy during water transit to the storage tank, the hot water temperature falls from $90^{\circ} \mathrm{C}$ at the outlet of the evacuated tube collector to $72^{\circ} \mathrm{C}$ at the inlet of the storage tank, which represents $20 \%$ of heat loss that is equivalent to $2360 \mathrm{Wh}$.

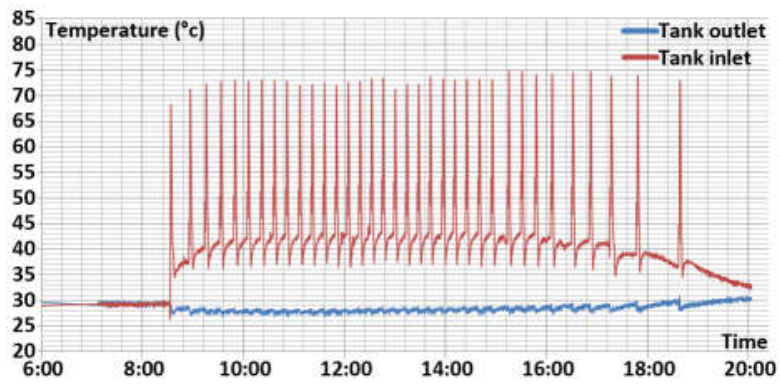

Fig. 7. Data logger - storage tank inlet and outlet temperatures during day period.

After draining the Fresnel mirrors concentrator, the obtained curve figure 8 shows that the maximum reached water temperature is $61{ }^{\circ} \mathrm{C}$ while the extracted thermal energy is $5846 \mathrm{Wh}$, the maximum output temperature falls from $72{ }^{\circ} \mathrm{C}$ to $61^{\circ} \mathrm{C}$ due to the mixture between hot and cold water already contained inside the tank, in order to avoid this temperature drop, the 200L storage tank must be replaced with a suitable capacity of 120 to $150 \mathrm{~L}$.

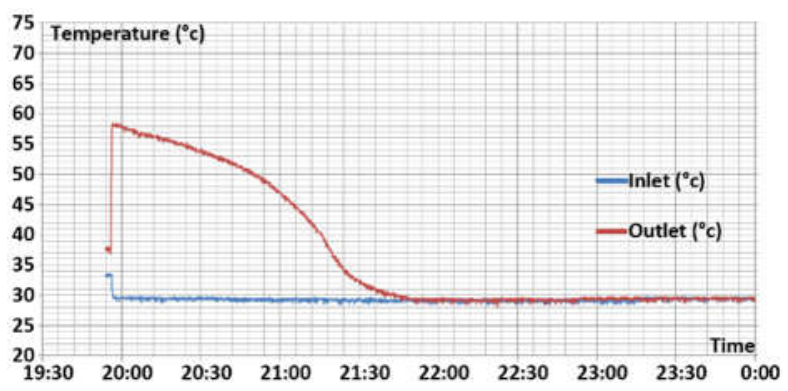

Fig. 8. EM2 - draining Fresnel concentrator's storage tank at the end of the day.

The difference on the temperature curves shape, between the evacuated tube collector and the flat plate collector, is related to the hot water storage tanks internal heat exchanger dimensions, which leads to either giving a stable temperature for a long time, or giving an intense temperature for a short time, and a rapid drop on temperature. 
Table 2 summarizes all obtained results of this comparative study.

Table 2. Summary table of the experimental results

\begin{tabular}{|c|c|c|c|}
\hline Technology & $\begin{array}{c}\text { Fresnel } \\
\text { concentrator }\end{array}$ & $\begin{array}{c}\text { Evacuated } \\
\text { tube } \\
\text { collector }\end{array}$ & $\begin{array}{c}\text { Flat } \\
\text { plate } \\
\text { collector }\end{array}$ \\
\hline Area $\left(\mathrm{m}^{2}\right)$ & 2.30 & 3.15 & 1.97 \\
\hline Capacity (L) & 200 & 200 & 200 \\
\hline $\begin{array}{c}\text { Energy production } \\
\text { (Wh) }\end{array}$ & 8256 & 9956 & 5357 \\
\hline $\begin{array}{c}\text { Energy production } \\
\left.\text { (Wh/m }{ }^{2}\right)\end{array}$ & 3585.8 & 3156.6 & 2715.3 \\
\hline Efficiency (\%) & 48.0 & 42.3 & 36.3 \\
\hline $\begin{array}{c}\text { Day period tubing } \\
\text { losses (Wh) }\end{array}$ & 2360 & 0 & 0 \\
\hline Tubing losses (\%) & 26.1 & 0 & 0 \\
\hline $\begin{array}{c}\text { Max temperature } \\
\left({ }^{\circ} \mathrm{C}\right)\end{array}$ & 90 & 68.5 & 54.25 \\
\hline $\begin{array}{c}\text { Circulating pump } \\
\text { consumption } \\
\text { (KWh) }\end{array}$ & 0.04 & 0 & 0 \\
\hline
\end{tabular}

The experimental comparative study [19] done in Dublin city, concludes that during all the seasons the evacuated tube collector system have always higher efficiency than the flat plate collector system, with $49 \%$ for the evacuated tube collector and $31 \%$ for the flat plate collector, and an average tubing losses of $17.1 \%$. This comparative study [20] was performed by the use of numerical simulations using TRNSYS 16 software, the simulation was done for three distinct geographic areas that differs notably from each other, Naple in Italy, Kabul in Afghanistan and Stockholm in Sweden, the simulation compares a string of 4 flat plate collectors with another string of 4 evacuated tube collectors all long the year, and conclude that the evacuated tube collectors are more efficient on both cold and hot weather and reach a higher output water temperature, while the flat plate collectors efficiency drops drastically during cold weather, when users need hot water the most. By taking into consideration the differences between climates, the technical installation, the tools and sensors and the used solar water heaters brands, we can conclude that the thermal station test bench provides a coherent data and results, in order to test any kind of solar water heater brand or concept.

\section{Conclusion}

The test bench thermal station allowed to test the performances of 3 solar water heaters, the station is able to test any type of solar water heaters under the same weather conditions, the experiment shows that under normal weather condition, the Fresnel mirrors concentrator have the best efficiency at its output that reach $48 \%$, followed by the evacuated tube collector that have a efficiency of $42.3 \%$, then come at the last position the flat-plate collector with an efficiency $36.3 \%$, in addition to that, the Fresnel mirrors concentrator allows to reach higher water temperature at its output, even if the sun power is not at its maximum power, thanks to the use of hot water circulating pumps.

LERED laboratory is open to any other organization to exploit this test bench to test and compare any type of solar water heater technologies.

\section{Acknowledgement}

This work was supported by IRESEN the research institute for solar energy and new energies under the aegis of the ministry of energy and mining, and the Faculty of Science and Technology Settat City under the aegis of Hassan 1st University. Furthermore, the authors are grateful to Mr. Othmane Maakoul for his support during all stages of the project.

\section{References}

1. T. M. Letcher, in Manag. Glob. Warm. (Elsevier, 2019), pp. 3-15

2. R. M. Elavarasan, Eur. J. Sustain. Dev. Res. 3, (2019)

3. J. Jurasz, F. A. Canales, A. Kies, M. Guezgouz, and A. Beluco, Sol. Energy 195, 703 (2020)

4. R. Prăvălie, C. Patriche, and G. Bandoc, J. Clean. Prod. 209, 692 (2019)

5. G. Mokhtar, B. Boussad, and S. Noureddine, Case Stud. Therm. Eng. 8, 176 (2016)

6. V. K. Jebasingh and G. M. J. Herbert, Renew. Sustain. Energy Rev. 54, 1085 (2016)

7. G. L. Morrison, I. Budihardjo, and M. Behnia, Sol. Energy 76, 135 (2004)

8. I. Budihardjo and G. L. Morrison, Sol. Energy 83, 49 (2009)

9. D. Rojas, J. Beermann, S. A. Klein, and D. T. Reindl, Sol. Energy 82, 746 (2008)

10. M. L. T. Moncada, B. C. Muñoz, M. M. Yoshida, and R. D. Rodríguez, Energy Procedia 57, 2131 (2014)

11. E. Zambolin and D. Del Col, Sol. Energy 84, 1382 (2010)

12. M. Moldovan, I. Visa, and B. Burduhos, J. Sustain. Dev. Energy Water Environ. Syst. 8, 293 (2020)

13. M. Zell, J. G. Lyng, D. J. Morgan, and D. A. Cronin, J. Food Eng. 93, 344 (2009)

14. K. Dusarlapudi, B. K. Nashine, and M. D. Bai, 9 (n.d.)

15. R. C. Baker and M. V. Morris, Trans. Inst. Meas. Control 7, 209 (1985)

16. A.-J. N. Khalifa, Renew. Energy 14, 77 (1998)

17. Z. Li, C. Chen, H. Luo, Y. Zhang, and Y. Xue, Sol. Energy 84, 1413 (2010)

18. A. Hobbi and K. Siddiqui, Sol. Energy 83, 700 (2009)

19. L. M. Ayompe, A. Duffy, M. Mc Keever, M. Conlon, and S. J. McCormack, Energy 36, 3370 (2011)

20. A. Greco, E. Gundabattini, D. S. Gnanaraj, and C. Masselli, Climate 8, 78 (2020) 